\title{
Active or Lazy: What Motivates Workplace Performance?
}

\author{
Anna Leybina, Amanda Ong Hui Zhong \\ Raffles College of Higher Education, Singapore
}

\author{
Mergalyas M. Kashapov \\ Yaroslavl State University, Yaroslavl, Russia
}

\begin{abstract}
This article describes the pilot research aimed to define motives lying behind counterproductive behavior (procrastination) during creative task performance. The main hypothesis was that the level of procrastination varied depending on the needs and values that prevail in employees was approved. It was found that need in self-actualization, values of stimulation and achievement predict low level of procrastination, while need in comfort and safety and value of conformity predict high level of procrastination.
\end{abstract}

Keywords: motivation, needs, values, creativity, counter-productive behavior, procrastination

Today's businesses prioritize work effectiveness and psychology is looking for ways to improve human resources. One of the major job performance parameters is professional productivity, which is defined as the effective use of professional resources to achieve the goal (Druzhilov, 2003). While one part of productivity research is devoted to studying the factors that increase productivity (Munchinsky, 2006), another part of the research is interested in understanding the counterproductive workplace behavior which are destruction of property, misuse of information, poor-quality work, alcohol, inappropriate verbal and physical actions and misuse of time (Cullen \& Sakett, 2003). The last component has recently attracted a lot of scientific attention and received the term workplace procrastination. It is said to bring significant money losses to companies and employees (Ferrari, 2010; Steel, 2007). There were a number of researches done to study motivation influencing the productivity of job performance, but limited amount of researches discussed the motivation behind counter-productive behavior and, particularly, behind workplace procrastination.

\section{Work Motivation}

The whole set of driving forces that stimulate person activity at the workplace and have a certain goal orientation may be called work motivation, and it is defined by Pinder (1998) as "a set of energetic forces that originate both within as well as beyond an individual's being, to indicate work related behavior and determine its form, direction, intensity and duration" (as cited in Munchinsky, 2006, p. 391).

Motivation was defined by Pitchard, Harrell, DiazGrandos, and Guzman (2008) as a resource (energy pool) allocation process whereby energy spreads across actions and tasks to maximize the person's needs satisfaction.

One of the most discussed motivation theories is the Need Hierarchy Theory (Maslow, 1970) which differentiates among the following five types of needs that most people behave to satisfy: physiological, safety, social, self-esteem and self-actualization. At any particular time, a person has certain needs to satisfy. However, satisfaction is not limited to simply meeting one's needs. Other factors like personal values are also involved.

Anna Leybina, Ph.D., lecturer, Raffles College of Higher Education.

Amanda Ong Hui Zhong, Raffles College of Higher Education.

Mergalyas M. Kashapov, Ph.D., professor, Yaroslavl State University. 
Personal values refer to personal goals that are able to stimulate human behaviors and regulate workplace performance in order for people to achieve their goals (Bojovich, 1995; Gannon, 2002; Schwartz, 2006).

Thus, in the research we considered needs and personal values as regulators of professional performance.

The general assumption of the research was that people will differ in the level of procrastination depending on the needs and values that prevail in them.

\section{Procrastination, Laziness and Performance}

Procrastination is the purposive and frequent delay in beginning or completing a task to the point of experiencing subjective discomfort (Diaz-Morales, Cohen, \& Ferrari, 2008). It can be characterized by counterproductive, needless and delaying behavior (Shraw, Wadkins, \& Olafson, 2007). Chronic procrastinators are characterized by people with low motivation, but gross laziness (Ferrari, Johnson, \& McCown, 1995).

Even if most researchers considered procrastination and laziness as synonymous (Ferrari, 1991; Thakkar, 2009), there were still some researchers who claimed that procrastination is not the same as laziness (Basco, 2010). Some people spend more time procrastinating and others delay or interrupt their work with counterproductive activities occasionally.

Nevertheless, being manifested from counterproductive behavior, procrastination is said to negatively affect workplace performance. Steel (2007) and Mehrabian (2000) found a strong negative relationship between performance/career success and procrastination. In addition, delays made until deadline and the problems caused by that were discussed by Gersick (1989) and Ferrari (2010).

\section{Creativity}

In discussions of professional activity, professional creativity often is claimed to be more favorable and is said to require much more resources (Amabile, 1996; Woodman, Sawyer, \& Griffin, 1993) than in comparison with a routine performance (Borman \& Motowidlo, 1997).

Career commitment is significantly greater in people with radical creativity than in people with incremental creativity and routine performance (Madjar, Greenberg, \& CHEN, 2011). It might look like creative task which attracts more interest and, thus, reduces procrastination, however, it was found out that creativity sometimes takes more time than necessary to finish the task (Cohen \& Ferrari, 2010; Schraw et al., 2007). The search for inspiration or new ideas may lead to procrastination, however, it was discovered that the link between creative process and procrastination is very weak for people who usually do not delay finishing the task.

That is the reason why it may be more reasonable to understand the effect of procrastination on productivity by assessing the results of a creative task. But it is also not clear on what exactly motivates employees to be creative, because nowadays we have very limited knowledge about motivators of creativity or routine work (Ford, 1996; Unsworth \& Clegg, 2010).

Schwartz value theory (2006) has ten values that form a motivational continuum with two bipolar dimensions: openness to change (hedonism, self-direction and stimulation) and resistance to change (security, conformity and tradition). It was mentioned that openness to changes is one of the important characteristics for professional creative activity (Amabile, 1996; Bojovich, 1995).

Authors defined motivation of professional creativity as a motivation that has highly inspired thinking as its basis that leads to the creation of new ways, means and methods of performing professional task. As a result, 
it forms and improves significant social and professional qualities (Kashapov, 2006).

Thus, the research was aimed to understand the effect of motivation on procrastination during the creative task performance.

\section{Motivation of Procrastination}

There is not much said about the different types of employees' motivation that influence their counterproductive behaviors or procrastination. However, existing findings in the field of procrastination can help us to build assumptions.

Ferrari (2010) mentioned that people delay a lot of tasks without regard of the needs these tasks satisfy. At the same time, people will procrastinate if they expect that their needs are not going to be met. We may say that there are no definite answers if needs or values will affect level of procrastination. However, we are able to build some hypotheses based on the researches done in the field of procrastination.

According to Ferrari (1991), procrastinators are interested in strengthening their social skills. Barron (1988) pointed out that conformity usually restricts creativity (as cited in Andriopoulos, 2001). Thus, we hypothesized that the need in communication and belonging, as well as value of conformity (it was also mentioned earlier as related to resistance to changes) would positively predict the level of procrastination.

Self-actualization need, which represents the need to be the best we can be, was connected to perfectionism by Ferrari (2010) and assumed that it would positively predict the delay in tasks. Striving for achievement and self-actualization is acknowledged as aspects of perfectionism (Frost, Marten, Lahart, \& Rosenblate, 1990; as cited in Walsh \& Ugumba-Agwunobi, 2002). However, self-handicapping behavior and motivation was found in procrastinators (Ferrari, 2010), which tells us that procrastinators may have a low development of achievement value. Thus, we hypothesized that need in self-actualization would be positively related to perfectionism, while value of achievement would be related negatively.

Procrastinators delay tasks to avoid discomfort (Ferrari, 2010), Steel (2007) has discovered that people increase their procrastination while in the anxious state. Sensation seeking has been found to have low correlations with procrastination (Steel, 2007). At the same time, Ferrari (2010) mentioned that procrastinators like to delay tasks because they like the thrill of the last minute rush. Thus, we hypothesized that need in comfort and safety, as well as value of safety would predict low level of procrastination, while values of stimulation and hedonism would predict high level of procrastination.

Choi and Moran (2009) claimed that procrastination may be active. The word "active" refers to a category called active procrastinators. These individuals purposely put off work until the deadline because they perform better when under pressure. For active procrastinators, they plan the schedules beforehand and make time for other unrelated activities, until the deadline nears, whereby they then get their motivation to finish up their original work when challenged by time factors (Chu \& Choi, 2005; Deci \& Ryan, 1985).

However, Ferrari (2010) argued their opinion, stating that procrastinating is opposite to being active. Opposite of active procrastination is passive procrastination (Chu \& Choi, 2005). Passive procrastination or normal procrastination is described as people who refrain from working on their original assignments and is more inclined to do other things that give more gratification (Tice \& Baumeister, 1997). Contributing factors can simply be a dislike for the task (Steel, 2007). Burka and Yuen (1983) referred to this as an irrational delay because the person holds off doing work, despite of knowing that the outcome will not turn for the better (Steel, 2007). This is in contrast to active procrastinators who know that they will achieve the results that they want. 
Procrastination due to task aversion, anxiety or inability to meet perfection (Burka \& Yuen, 1982) is more plausible than procrastinating to get motivation (active procrastinator), and this was supported by Ellis and Knaus (1977) who approximated that about $95 \%$ of college students procrastinate.

Thus, we hypothesized that motivation of general activity (discussed below) would negatively predict the level of procrastination.

Hypothesis 1: The level of procrastination will vary depending on the needs and values that prevail in employees.

Hypothesis 2: Motivation of general activity, comfort, values of safety and achievement will positively predict the productivity in creative task, while motivation of self-actualization, communication and belonging, value of hedonism and stimulation and conformity will negatively predict productivity in creative task due to procrastination.

The effect of remaining needs and values (physiological need, self-esteem, value of power, benevolence, universalism, self-direction and tradition) was not included in our study, because their relations with procrastinating behavior are unclear.

\section{Method}

\section{Participants and Procedure}

We conducted our research on 49 employees in Russia, being not precise in differentiating the participants by their gender, age, marriage or education because previous researches reported in Ferrari (2010) found no significant differences at level of procrastination depending on these socio-demographic characteristics. Thirty women and 19 men participated in the research. The mean age was $31, S D=3.45$.

We contacted 80 employees that have already participated in Yaroslavl State University researches and invited them to participate in the study. We explained that the research studied possible effect of personal qualities on employee performance, and at the end of the task, they would be given the feedback about their personal qualities. The response rate was $61.25 \%$.

Before completing assessments, participants were assigned code numbers and assured that all information would be kept confidential.

At the first stage, the participants completed the questionnaires that they had during their free time and were required to bring it along in order to participate in the professional thinking test. Each worker at the office room did the test separately. It took about 40 minutes. Besides the standard instruction, no additional stimuli or encouragement were used.

\section{Measures}

Diagnostic of creative productivity and procrastination was done using "Diagnostic of Professional Creative Thinking" method, developed by A. Leybina. The method passed the proper verification procedure of professional and personal development at the Yaroslavl State University in 2004 to 2006. The criteria of creativity and activity were used as main indicators of professional productivity. The diagnostic procedure was organized in the following way: The participants received the set of items (equal to each person) and the standard instruction. The test was completed within 15 minutes, but we made some changes to the instructions in order to assess procrastination. We told participants that they had to spend 40 minutes in the office. During that time limit, they had to complete the task. Generally, people required half of the allocated time to do the 
task. But because of the extra time, they were allowed to browse at the selection of magazines offered. After they were finished with the task, they had to say, "I am done!".

The following indicators were used:

(O) - the indicator of originality which is determined as the relation of concrete idea originality to the general amount of ideas (were assessed by the table of standard answers);

(F) - the indicator of fluency which is determined as the amount of ideas proposed in a given interval calculated by the formula $F=X / N$ where $X$ is amount of ideas and $N$ is the amount of minutes person spent from the beginning of the test till she/he said "I am done!". This parameter of the test showed the procrastination;

(C) - the indicator of complexity which is determined as the amount of ideas created;

(Fl) - indicator of flexibility, which is determined as the variety of the ideas related to the amount of ideas.

All the coefficients were calculated by E. P. Torrance formulas (as cited in Tunik, 2006).

Each activity was monitored and categorized as important (related to the task) and not important (not-related, like using personal phone, magazines browsing, etc.). The final creativity coefficient was multiplied on the amount gotten after dividing important activity on unimportant activity, which varied from 10 to 0.1 . The higher were the results for these test, the higher was productivity and the lower procrastination.

Needs were assessed using the method of personal motivational structure assessment (Milman, 1990). The questionnaire contained items that were created while considering labor activity and casual activity. The method assesses the following variables.

Life support motivation refers to pragmatic and physiological needs. Comfort and safety motivation refers to need for comfort and safety. Motivation of status and prestige refers to the need for self-assessment. Communication and belonging motivation refers to the need for communication and belonging. General activity motivation was described by Milman (1990) as the one reflecting vitality, subject's desire of energy and some activity (integrates physiological and comfort and safety needs). Creative activity motivation reflects the need for self-actualization, as well as motivation to be useful for society.

Personal values were assessed by Schwartz value inventory adapted by Karandashev (2004). The following value variables can be assessed using the questionnaire: power, achievements, hedonism, stimulation, self-direction, benevolence, universalism, tradition, conformity and safety.

It was already mentioned that the possibility of participants demographic characteristics that would confound the relationships examined was very low. We expected that political events or economical changes might affect the performance that why the research was done within one month (August, 2008). It was possible that time of the day and day of the week might also affect productivity, which was why the meetings with participants were conducted on Tuesdays, Wednesdays and Thursdays from 11:00 till 16:00 (two hours before or two hours after lunch). The participants were asked to come after the one-hour rest (that they were not rushing for lunch or resting during the test). All of the participants claimed to be in the proper state. Due to minimizing the influence of personal creativity, only the factors of fluency and important/unimportant tasks were used in "diagnostic of professional creative thinking".

\section{Results}

Table 1 shows mean and standard deviation for the variables.

A multiple regression was conducted to assess the effect of employees' different types of motivation and 
values at the level of activity (procrastination) in performing the task.

Table 1

Descriptive Statistic and Variable Inter-correlations $(N=49)$

\begin{tabular}{|c|c|c|c|c|c|c|c|c|c|c|c|c|c|c|c|}
\hline & $M$ & SD & 1 & 2 & 3 & 4 & 5 & 6 & 7 & 8 & 9 & 10 & 11 & 12 & 13 \\
\hline 1. Activity level & 23.37 & 9.20 & & & & & & & & & & & & & \\
\hline $\begin{array}{l}\text { 2. M- } \\
\text { General activity }\end{array}$ & 21.08 & 5.79 & -0.03 & & & & & & & & & & & & \\
\hline 3. M-Creativity & 24.90 & 7.80 & $0.87^{* *}$ & -0.02 & & & & & & & & & & & \\
\hline 4. M-Comfort & 21.88 & 6.13 & $-0.56^{* *}$ & $0.27^{*}$ & $-0.43^{* *}$ & & & & & & & & & & \\
\hline $\begin{array}{l}\text { 5.M-Useful fo } \\
\text { society }\end{array}$ & for 25.10 & 6.95 & $0.32^{*}$ & $0.49^{* *}$ & $0.31^{*}$ & -0.08 & & & & & & & & & \\
\hline $\begin{array}{l}\text { 6. M- } \\
\text { Communication }\end{array}$ & 23.53 & 6.20 & $-0.60^{* *}$ & 0.22 & $-0.45^{* *}$ & $0.90^{* *}$ & -0.07 & & & & & & & & \\
\hline 7. M-Basic needs & 19.76 & 6.27 & $-0.29^{*}$ & $0.51^{* *}$ & -0.14 & $0.63^{* *}$ & $0.24^{*}$ & $0.57^{* *}$ & & & & & & & \\
\hline 8. M-Status & 21.20 & 8.26 & 0.13 & $0.27^{*}$ & $0.28^{*}$ & $0.31^{*}$ & $0.41^{* *}$ & $0.27^{*}$ & $0.48^{* *}$ & & & & & & \\
\hline 9. V-Achievement & 10.88 & 7.10 & $0.75^{* *}$ & -0.14 & $0.73^{* *}$ & $-0.32^{*}$ & 0.16 & $-0.39^{* *}$ & -0.20 & 0.16 & & & & & \\
\hline 10. V-Hedonism & 10.16 & 5.59 & $0.40^{* *}$ & -0.05 & $0.27^{*}$ & -0.14 & 0.12 & $-0.27^{*}$ & -0.01 & -0.09 & $0.38^{*}$ & & & & \\
\hline 11. V-Stimulation & 16.61 & 9.45 & $0.52^{* *}$ & 0.08 & $0.39^{* *}$ & $-0.27^{*}$ & $0.28^{*}$ & $-0.30^{*}$ & -0.06 & 0.13 & 0.20 & $0.29^{*}$ & & & \\
\hline 12. V-Conformity & 12.12 & 6.45 & -0.16 & 0.01 & $-0.25^{*}$ & -0.04 & -0.07 & -0.04 & 0.02 & -0.21 & $-0.39^{* *}$ & -0.04 & 0.11 & & \\
\hline 13. V-Safety & 12.08 & 6.78 & $0.28^{*}$ & $0.26^{*}$ & 0.20 & -0.03 & 0.16 & -0.02 & 0.03 & $0.32^{*}$ & $0.34^{*}$ & 0.07 & $0.29^{*}$ & -0.10 & \\
\hline
\end{tabular}

Notes. $M=$ Motivation; $V=$ Value; ${ }^{*} P<0.05 ;{ }^{* *} P<0.01 ; S D$ : Standard deviation.

The value of $r^{2}$ was 0.93 (adjusted $r^{2}$ was 0.88 ), a value that was highly significant $\left(F_{(20,28)}=19.06, p<\right.$ $0.001)$. The standard error of the estimate was 3.15 .

Some independent variables alone correlated significantly with the dependent variable, as it is shown in Table 1: motivation of creativity $(r=0.87, p<0.01)$, motivation of comfort $(r=-0.56, p<0.01)$, motivation of being useful for society $(r=0.32, p<0.05)$, motivation of communication $(r=-0.60, p<0.01)$, value of achievement $(r=0.75, p<0.01)$, value hedonism $(r=0.40, p<0.01)$, value stimulation $(r=0.52, p<0.01)$, and value safety $(r=0.28, p<0.05)$.

Semipartial $r$ values and values of beta for all the independent variables are shown in Table 2 together with the results of significance test. The following independent variables were accounted for the significant amount of unique variance of the dependent variable.

The motivation of creativity ( $b e t a=0.36, p<0.01$ ) contradicts to our hypothesis. We expected that people with higher motivation of creativity would procrastinate more, however, it is obvious that they procrastinated less.

Motivation of comfort and safety (beta $=-0.38, p<0.05$ ) was opposite to our hypothesis. Whereas it was predicted that procrastination would be lower in those who need comfort and safety, it was actually found that they had higher level of procrastination.

Value stimulation (beta $=0.26, p<0.01$ ) contradicted to our hypothesis. It was expected that employees with higher stimulation orientation would procrastinate more, however, they procrastinated less.

Value of hedonism, motivation of general activity, to be useful for society, communication and belonging appeared to be not able to predict procrastination, which, again, contradicted our hypothesis.

However, our predictions about value of achievement (beta $=0.31, p<0.01)$ were supported. Value of achievement was shown to be negatively related with procrastination.

The expectations towards value of conformity (beta $=-0.16, p<0.05$ ) were also proven. This variable was 
able to positively predict level of procrastination.

We should notice that even if our Hypothesis 2 was approved only partially, Hypothesis 1 that people will differ in the level of procrastination depending on the needs and values that prevail in them has been proven.

Table 2

Semipartial r-Values and Beta Values Together With Significance Tests for Independent Variables in the Multiple Regression Analysis

\begin{tabular}{lcccl}
\hline & \multicolumn{3}{c}{ Coefficients } \\
\cline { 2 - 5 } Variable & Semi-partial $r$ & beta & \multicolumn{1}{c}{ sig. } \\
\hline 1. Activity level & & & 0.95 & 0.006 \\
2. M-General activity & 0.042 & 0.068 & 3.40 & 0.401 \\
3. M-Creativity & 0.168 & 0.358 & -2.34 & 0.002 \\
4. M-Comfort & -0.116 & -0.383 & 1.07 & 0.026 \\
5. M-Useful for society & 0.053 & 0.078 & 0.76 & 0.293 \\
6. M-Communication & 0.038 & 0.117 & -0.43 & 0.452 \\
7. M-Basic needs & -0.021 & -0.041 & 0.69 & 0.672 \\
8. M-Status & 0.034 & 0.062 & 2.77 & 0.493 \\
9. V-Achievement & 0.137 & 0.312 & 0.94 & 0.010 \\
10. V-Hedonism & 0.046 & 0.063 & 3.51 & 0.355 \\
11. V-Stimulation & 0.174 & 0.257 & -2.368 & 0.002 \\
12. V-Conformity & -0.224 & -0.161 & -0.08 & 0.025 \\
13. V-Safety & -0.004 & -0.006 & 0.936 \\
\hline
\end{tabular}

Notes. $M=$ Motivation, $V=$ Value.

\section{Discussion}

It was found out that needs and values can predict the level of employees' motivation during the creative task performance.

High orientation on achievement value can predict low level of procrastination, which goes in accordance with theory (Ferrari, 2010). People, suffering from learned helplessness and self-handicapping behavior, may react with anxiety towards a task that seems tough or complicated for them. On the contrary, people with achievement value are guided by the idea of overcoming difficulties, reaching the highest level with lesser regards to the challenge (Schwartz, 2006).

High value of conformity makes employees look for accepted structures and strategies (Schwartz, 2006), thus, tasks that require a great deal of creativity might be frustrating for them. Their procrastination may have been produced by an expectation of guidance and clear ideas, and it could somehow be difficult for them to deal with a task that was expected to be assessed by others (researchers). This supports the theory and confirms our predictions. There are several needs and values that have been found to affect procrastination differently, judging from the conclusions made based on the literature review.

Motivation of creativity, which represents the need in self-actualization (together with motivation of commonwealth which has been found to have negative correlation with procrastination), is able to predict low level of procrastination, in addition to being expected to correlate with high procrastination. This finding can be explained by the results from Cohen and Ferrari (2010). Even if creativity may require more time to finish the task in comparison with simple replication, it can actually lead to faster performance. We can make a conclusion that the need in self-actualization may not necessarily lead to procrastination, for it can even reduce 
the procrastination unless the trait perfectionism is involved.

It has been found out that the need in comfort and safety predicts high level of procrastination while value of stimulation predicts low level of procrastinating behavior in creative task. This finding may clarify the question that Ferrari (2010) raised in his latest work; in that thrill is the consequence but not something that procrastinators has been originally looking for. Farley frequently emphasized the thrill-seeking trait of creative people (Barron, 1988; Farley, 1981). According to Maslow's Need Hierarchy (1970), the needs of higher order (self-actualization) cannot be met unless the needs of the lower order are satisfied. Thus, we may assume that individuals with low level of safety need satisfaction will get no or low interest in creative task which may lead to procrastination. This may be supported with the fact that the need in communication and belonging sowed highly significant positive relations with procrastination level.

\section{Future Research}

The research conducted can be considered as a pilot. Due to limited amount of participants, we have been not able to provide the full exploration of motivation laying behind counterproductive behavior in creative tasks. We expect to enlarge the number of participants to confirm our findings and build the structural equation model of motivation of procrastinators. It may be also useful to conduct not one but several assessments of procrastination (e.g., self-reports and expert assessments provided by managers and supervisors), in order to decrease the influence of other factors on the performance. We assume that the characteristics of the task, personal issues or some other motivational factors may affect creative performance of the participants.

\section{Conclusions}

Counterproductive behavior has become a widely discussed problem in today's society. Psychology science has discussed the topic of motivation: "How should we motivate people to work better?", but so far, nothing has been mentioned about what motivates counterproductive behavior. It is obvious that employees who practice counterproductive behavior are similar to productive employees, in terms of motives and values. In our opinion, knowledge of motives and values that are present in counterproductive employees will open a lot of opportunities for trainings and assessment and may also help to deal with such a problem as workplace procrastination. The results of discussed research have shown that procrastination would be dependent on the motives that prevail in employees and it is possible to predict the level of procrastination by assessing needs and values of the worker. Need in self-actualization, values of stimulation and achievement predict low level of procrastination, while need in comfort and safety as well as value of conformity predict high level of procrastination.

\section{References}

Amabile, T. M. (1996). Creativity in context. Boulder, C. O.: Westward Press.

Andriopoulos, C. (2001). Determinants of organizational creativity: A literature review. Management Decision, 39, 834-841.

Basco, M. R. (2010). The procrastinator's guide to getting things done. USA: The Guilford Press.

Bojovich, L. I. (1995). Selected psychology works: Problems of personality forming. Moskva: Mezhdunarodnaya pedagogicheskaya akademiya Publishing.

Borman, W. C., \& Motowidlo, S. J. (1997). Task performance and contextual performance: The meaning of personnel selection research. Human Performance, 10, 99-109. doi: 10.1207/s15327043hup1002_3

Burka, J. B., \& Yuen, L. M. (1982). Mind games procrastinators play. Psychology Today, 44, 32-34.

Burka, J. B., \& Yuen, L. M. (1983). Procrastination: Why do you do it, what to do about it. M. A.: Addison-Wesley. 
Choi, J. N., \& Moran, S. V. (2009). Why not procrastinate? Development and validation of a new active procrastination scale. Journal of Social Psychology, 149, 195-211.

Chu, A. H. C., \& Choi, J. N. (2005). Rethinking procrastination: Positive effects of "active" procrastination behavior on attitudes and performance. The Journal of Social Psychology, 145, 245-264.

Cohen, J. R., \& Ferrari, J. R. (2010). Take some time to think this over: The relation between rumination, indecision, and creativity. Creativity Research Journal, 22, 68-73.

Cullen, M. J., \& Sakett, P. R. (2003). Personality and counterproductive workplace behavior. In M. R. Barric, \& A. M. Ryan (Eds.), Personality and work: Reconsidering the role of personality in organizations (pp. 149-165). San Francisco: Jossey-Bass.

Deci, E. L., \& Ryan, R. M. (1985). Intrinsic motivation and self-determination in human behavior. New York: Plenum Press.

Diaz-Morales, J. F., Cohen, J., \& Ferrari, J. R. (2008). An integrated view on personality styles related to avoidant procrastination. Personality and Individual Differences, 45, 554-558.

Druzhilov S. A. (2003). Professionalism as a target of psychology research: System approach. Baltic Pedagogy Academy of Herald, 52.

Ellis, A., \& Knaus, W. J. (1977). Overcoming procrastination. New York: Institute for Rational Living.

Ferrari, J. R. (1991). A preference for a favorable public impression by procrastination: Selecting among cognitive and social tasks. Personality and Individual Differences, 12, 1233-1237.

Ferrari, J. R., Johnson, J. L., \& McCown, W. G. (1995). Procrastination and task avoidance. New York: Premium Press.

Ferrari, J. R. (2010). Still procrastinating: The no-regrets guide to getting it done. New York: John Wiley \& Sons, Inc..

Ford, C. M. (1996). A theory of individual creative action in multiple social domains. Academy of Management Review, 21, 1112-1142. doi: $10.2307 / 259166$

Gannon, M. J. (2002). Handbook of cross-cultural management. New Jersey: Whiley-Blackwell.

Gersick, C. J. G. (1989). Making time: Predictable transitions in tasks groups. Academy of Management Journal, 33, 274-309.

Karandashev, V. N. (2004). Chwartz personal value inventory: Description and manual. SPb: Rech.

Kashapov, M. M. (2006). Psychology of professional creative thinking. Moskva: PER SE.

Maslow, A. H. (1970). Motivation and personality. New York: Harper \& Row.

Madjar, N., Greenberg, E., \& Chen, Z. (2011). Factors of radical creativity, incremental creativity, and routine, noncreative performance. Journal of Applied Psychology. Advance online publication. doi: 10.1037/a0022416

Mehrabian, A. (2000). Beyond IQ: Broad-based measurement of individual success potential or "emotional intelligence". Genetic, Social, and General Psychology Monographs, 126, 133-239.

Munchinsky, P. M. (2006) Psychology applied to work (8th ed.). Stamford: Thomson Wadsworth.

Milman, V. E. (1990). The method of personal motivation structure assessment. Moskva.

Pitchard, R. D., Harrell, M. M., DiazGrandos, D., \& Guzman M. J. (2008). The productivity measurement and enhancement system: A meta-analysis. Journal of Applied Psychology, 93, 540-567.

Schraw, G., Wadkins, T., \& Olafson, L. (2007). Doing the things we do: A grounded theory of academic procrastination. Journal of Educational Psychology, 99, 12-25. doi:10.1037/0022-0663.99.1.12

Schwartz, S. H. (2006). Basic human values: Theory, measurement and applications. Revue Française da Sociologie, 47, 929-968.

Steel, P. (2007). The nature of procrastination: A meta-analytic and theoretical review of quintessential self-regulatory failure. Psychological Bulletin, 133, 65-94.

Thakkar, N. (2009). Why procrastinate: An Investigation of the root causes behind procrastination. Lethbridge Undergraduate Research Journal, 4. Retrieved from http://www.lurj.org/article.php/vol4n2/procastinate.xml

Tice, D., \& Baumeister, R. F. (1997). Longitudinal study of procrastination, performance, stress, and health: The cost and benefits of dawdling. Psychological Science, 8, 454-458.

Tunik, E. E. (2006). Creativity assessment. Test by E. Torrance (Adapted version). Sankt-Peterburg: Rech.

Unsworth, K. L., \& Clegg, C. W. (2010). Why do employees undertake creative action? Journal of Occupational and Organizational Psychology, 83, 77-99.

Walsh, J. J., \& Ugumba-Agwunobi, G. (2002). Individual differences in statistics anxiety: The roles of perfectionism, procrastination and trait anxiety. Personality and Individual Differences, 33, 239-251.

Woodman, R. W., Sawyer, J. E., \& Griffin, R. W. (1993). Toward a theory of organizational creativity. Academy of Management Review, 18, 293-321. doi: 10.1037/0021-9010.88.3.413 